\title{
Health-related quality of life and its correlates among rectal cancer survivors, Northwest of Iran
}

\author{
Nayyereh Aminisani', Mehdi Fatemi', Parvin Sarbakhsh', Alireza Nikanfar ${ }^{2}$, Amirtaher Eftekharsadat ${ }^{3}$, \\ Esmat Jafari' \\ ${ }^{1}$ Epidemiology and Statistics Department, Faculty of Health Sciences, Tabriz University of Medical Sciences, Tabriz 5165665931, Iran. \\ ${ }^{2}$ Haematology and Oncology Research Center of Tabriz University of Medical Sciences, Tabriz 5165665123, Iran. \\ ${ }^{3}$ Pathology Department, Emam Reza Hospital, Tabriz 5165665123, Iran.
}

Correspondence to: Dr. Nayyereh Aminisani, Epidemiology and Statistics Department, Faculty of Health Sciences, Tabriz University of Medical Sciences, Tabriz 5165665931, Iran. E-mail: aminisani_n@hotmail.com

How to cite this article: Aminisani N, Fatemi M, Sarbakhsh P, Nikanfar A, Eftekharsadat A, Jafari E. Health-related quality of life and its correlates among rectal cancer survivors, Northwest of Iran. J Cancer Metastasis Treat 2017;3:209-16.

Article history:

Received: 14 Jul 2017

Accepted: 21 Sep 2017

Published: 29 Sep 2017

Key words:

Health,

quality of life,

rectal cancer,

treatment,

socioeconomic status

\begin{abstract}
Aim: The objective of this study was to examine the health-related quality of life (HRQOL), and its correlates among rectal cancer survivors. Methods: This cross-sectional study was conducted in the northwest of Iran. Rectal cancer survivors were selected from teaching hospitals. HRQOL was estimated using the European Organization for Research and Treatment of Cancer Quality-of-Life Questionnaire C30. Information about sociodemographic, lifestyle and clinical features of disease was obtained by trained interviewers. Results: A total of 96 patients were included in this study with mean age of $57.31 \pm 14.15$ years, $54 \%$ were male and $59 \%$ over 55 years of age. Women performed poorer than men in many dimensions of HRQOL $(P<0.05)$. Total score of symptoms was higher in those who had a higher stage of the disease. Participants with insufficient physical activity had a lower score in physical and role dimensions and a higher score of pain and fatigue $(P$ $<0.05)$. In multiple regression models, treatment, stage of disease, and physical activity were important predictive factors of HRQOL. Conclusion: Some clinico-epidemiological factors were associated with a reduced score of HRQOL and its dimensions in this study. Overall, better performance in the presence of a modifiable factor; physical activity, is an opportunity for interventional strategies to improve the HRQOL.
\end{abstract}

\section{INTRODUCTION}

Colorectal cancer (CRC) is the second common cancer in female and the third in men, with an estimation of about 1.5 million incident cases and almost 700,000 deaths in $2012^{[1]}$. There is a geographical variation in the incidence of CRC around the globe with over 10-fold difference between the highest and lowest estimated incidence in 2012. The highest incidence has been reported from Australia, New Zealand, Europe and 
North America and the lowest incidence rates belonged to Africa and south-central Asia ${ }^{[1]}$. Variation might be explained by differences in genetic susceptibility, dietary habits and environmental exposures ${ }^{[2]}$. Recent advances in treatment and management of CRC have improved control and disease-free survival[ ${ }^{[3]}$.

Nowadays, the standard strategy in the management of CRC is a multidisciplinary approach to treatment especially for management of rectal cancer which is one of the great challenges and responsibility of the colorectal surgeons. The main goal is to improve survival, to minimise morbidity and to maximise the quality of life of the rectal cancer patients ${ }^{[4,5]}$.

Health-related quality of life (HRQOL) is a multidimensional concept that covers a range of the subjective perceptions from physical, emotional, social, and cognitive functions to disease symptoms and treatment side effects among cancer patients ${ }^{[6]}$. In CRC, the assessment of HRQOL is critical, and a range of various factors including socio-demographic characteristics, lifestyle, surgical procedures, and health-related factors are associated with $\mathrm{HRQOL}$ of patients with $\mathrm{CRC}^{[7]}$. Although, $\mathrm{HRQOL}$ assessment is important in evaluating the treatment options for rectal cancer (RC) patients, data on assessment of the quality of life among RC patients in the presence of a range of socio-demographic, lifestyle behaviours and clinical factors are scarce.

There are few cross-sectional studies which have assessed the quality of life among this group of patients in which some included few cases, or focused on treatment options only or did not include lifestyle factors $^{[7-9]}$. There is a relatively large prospective study that showed the anterior resection and non-stoma patients, despite suffering micturition and defecation problems, had a better quality of life scores than abdominoperineal extirpation and stoma patients ${ }^{[10]}$. A longitudinal study with 19 months follow-up, evaluated HRQOL in patients with RC using the functional assessment of cancer therapy-colorectal instrument and reported no differences in HRQOL by either tumour location or type of surgery, at either 9 or 19 months after diagnosis. These prospective studies were also focused on clinical aspects of QOL.

In Iran, CRC is one of the common cancers and is ranked the third and fifth most common cancer in women and men respectively. The age-standardized incidence rates in men and women were 11.31 and 10.89 respectively ${ }^{[11]}$. Previous studies showed an increase in trend of this cancer in north of Iran and poor quality of life among CRC survivors ${ }^{[12,13]}$. However, the data was not specific to RC survivors because of the small sample size.

The studies on assessing HRQOL among CRC patients are limited, and we could not find any publication related to the quality of life of RC patients. The aim of this study was to assess the HRQOL and its determinants in patients diagnosed with RC referring to the specialty teaching hospitals in East Azerbaijan, northwest of Iran.

\section{METHODS}

This cross-sectional study was conducted in the city of Tabriz, East Azarbaijan province located in the northwest of Iran between 2014 and 2015. All newly diagnosed patients aged 18 and over who had been diagnosed less than one year presenting at the teaching hospitals regardless of stage at diagnosis and plans for treatment, were included in this study.

Demographic information including age, the level of education, employment status and place of residency was collected via self-report. Age was categorised into two categories; $<55$ and $\geq 55$ years, the level of education was classified as illiterate, literate, occupation classed into (paid work or out of work) and finally place of residency specified as either urban or rural. Patients were also asked whether they experienced various comorbid conditions (including heart disease, hypertension, chronic back pain, arthritis, stroke, osteoporosis, asthma, chronic obstructive pulmonary disease, stomach and/or intestinal condition). Three different treatment regimens were used in this cohort of stage I-III rectal cancer patients: (1) surgery only, surgery plus chemotherapy (surgery $+\mathrm{CT}$ ), surgery plus radiotherapy (surgery $+\mathrm{RT}$ ); (2) surgery plus adjuvant chemo-radiotherapy (surgery + CRT); and (3) CT only/RT only/CRT only.

European organization for research and treatment of cancer quality-of-life questionnaire (QLQ) C30 was completed from all participants by two trained interviewers. This scale is the core questionnaire for evaluating the QOL of cancer patients. It is a 30 -itemed instrument with a four-point scale, from "not at all" to "very much", for items 1 to 28; and a seven-point scale for items 29 and 30. The QLQ-C30 dimensions include the physical functioning (PF), role functioning (RF), cognitive functioning (CF), emotional functioning (EF), social functioning (SF), the general level of QOL and the symptoms scale (i.e. fatigue, pain). Each patient's scores were transformed into a 0-to-100 scale, where 0 denotes the worst and 100 the best on functioning scales. In contrast, the reverse scoring system was applied for symptoms where zero point denotes the 
best and 100 the worst on symptom scales.

\section{Statistical analysis}

Descriptive analysis was used to present data, mean and standard deviation (SD) was used for quantitative variables, and numbers and percentages were provided for categorical data. Data checked for normality and linearity where it was required. Total score of $\mathrm{HRQOL}$ and its dimensions score were as dependent variables in this study. Univariate and multivariate analysis performed to assess the association between a range of factors and HRQOL. Variables with a $P$ value less than 0.1 were included in the multiple linear regression models to identify predictors of HRQOL. A $P$-value of less than 0.05 was predetermined to be mean statistical significance, and SPSS version 21 was used for all data analyses.

Table 1: Clinico-epidemiological characteristics of patients with rectal cancer referring to specialty teaching hospitals in Tabriz, Northwest of Iran 2014-2015

\begin{tabular}{|c|c|c|}
\hline & Number & $\%$ \\
\hline \multicolumn{3}{|l|}{ Age group } \\
\hline$<55$ years & 39 & 40.6 \\
\hline$\geq 55$ years & 57 & 59.4 \\
\hline \multicolumn{3}{|l|}{ Gender } \\
\hline Male & 52 & 54.2 \\
\hline Female & 44 & 45.8 \\
\hline \multicolumn{3}{|l|}{ Marital status } \\
\hline Single/widowed & 19 & 19.8 \\
\hline Married & 77 & 80.2 \\
\hline \multicolumn{3}{|l|}{ Place of residence } \\
\hline Urban & 81 & 54.4 \\
\hline Rural & 15 & 15.6 \\
\hline \multicolumn{3}{|l|}{ Education } \\
\hline Illiterate & 42 & 44.7 \\
\hline Literate & 52 & 55.3 \\
\hline \multicolumn{3}{|l|}{ Occupation } \\
\hline No working & 38 & 39.6 \\
\hline Working & 58 & 60.4 \\
\hline \multicolumn{3}{|l|}{ Comorbidities } \\
\hline Yes & 55 & 57.9 \\
\hline No & 40 & 42.7 \\
\hline \multicolumn{3}{|l|}{ Smoking } \\
\hline Yes & 28 & 29.5 \\
\hline No & 67 & 70.5 \\
\hline \multicolumn{3}{|l|}{ Physical activity } \\
\hline Adequate & 15 & 15.6 \\
\hline Inadequate & 81 & 84.4 \\
\hline \multicolumn{3}{|l|}{ Income } \\
\hline$<7,000,000 \mathrm{R}$ & 27 & 36.0 \\
\hline$>7,000,000 \mathrm{R}$ & 48 & 64.0 \\
\hline \multicolumn{3}{|l|}{ Stage of disease } \\
\hline | \& || & 66 & 68.8 \\
\hline III \& IV & 17 & 17.7 \\
\hline \multicolumn{3}{|l|}{ Treatment } \\
\hline CT only/RT only/CRT & 15 & 15.6 \\
\hline Surgery only/surgery + CT/ & 36 & 37.5 \\
\hline \multicolumn{3}{|l|}{ surgery + RT } \\
\hline Surgery + CRT & 44 & 45.8 \\
\hline \multicolumn{3}{|l|}{ Stoma } \\
\hline Yes & 36 & 62.1 \\
\hline No & 22 & 37.9 \\
\hline
\end{tabular}

Total number might be different due to missing values. CT: chemotherapy; RT: radiotherapy; CRT: chemo-radiotherapy
This study received ethics approval from Tabriz University of Medical Sciences; Ethics Committee and all patients completed an informed consent form before the interview session.

\section{RESULTS}

A total of 96 newly diagnosed patients with rectal cancer were included in this study with a mean age $57.31 \pm 14.15$ years (min: 27 , max: 83 ). The majority of them were male (54\%), $59 \%$ were over 55 years of age and more than two-third resided in urban areas $(84 \%)$. About $45 \%$ of them had no education, and about $40 \%$ were out of work. Many of them (84\%) reported inadequate physical activity, 30\% smoked either a cigarette or waste pipe, $58 \%$ had at least one comorbidity, and the stage of the disease was $\mathrm{I} / \mathrm{II}$ in most of the cases $(69 \%), 46 \%$ had received surgery plus CRT as the treatment of choice [Table 1].

Table 2 shows the mean (SD) score for different dimensions of QOL according to socio-demographic factors. As it can be seen, the score of total QOL and its dimensions were not different between younger and older age groups. Women performed significantly poorer than men in EF, PF, and RF dimensions $(P<$ $0.05)$. Those who were not engaged in any work had a lower score in EF and RF dimensions $(P<0.05)$. Participants with insufficient physical activity had a lower score in PF and RF dimensions $(P<0.05)$. Women, those who were not working, and those with insufficient physical activity had higher scores in symptom total, pain and fatigue. Scores of total QOL and its dimensions were not different according to the place of residency and smoking. Although the study participants with no education had poorer scores in total QOL and all dimensions, and showed the higher scores of symptoms total, pain and fatigue, the difference was not statistically significant compaired to literate participants. Patients with lower income had significantly higher scores of total QOL, and EF dimension $(P<0.05)$. They performed better in all other dimensions and had a lower score in symptom-total, pain and fatigue, but it was not statistically significant.

Table 3 shows the mean (SD) score for different dimensions of QOL according to clinical factors. Only treatment option had a significant association with total QOL score. Total score of symptoms was higher in those who had a higher stage of disease, and those who had undergone CT/RT/or CRT only. Those who had undergone surgery plus CRT performed better in all subscales except CF, and they had lower scores in symptom total, pain and fatigue $(P<0.05)$. Comorbidities were associated with higher scores in 


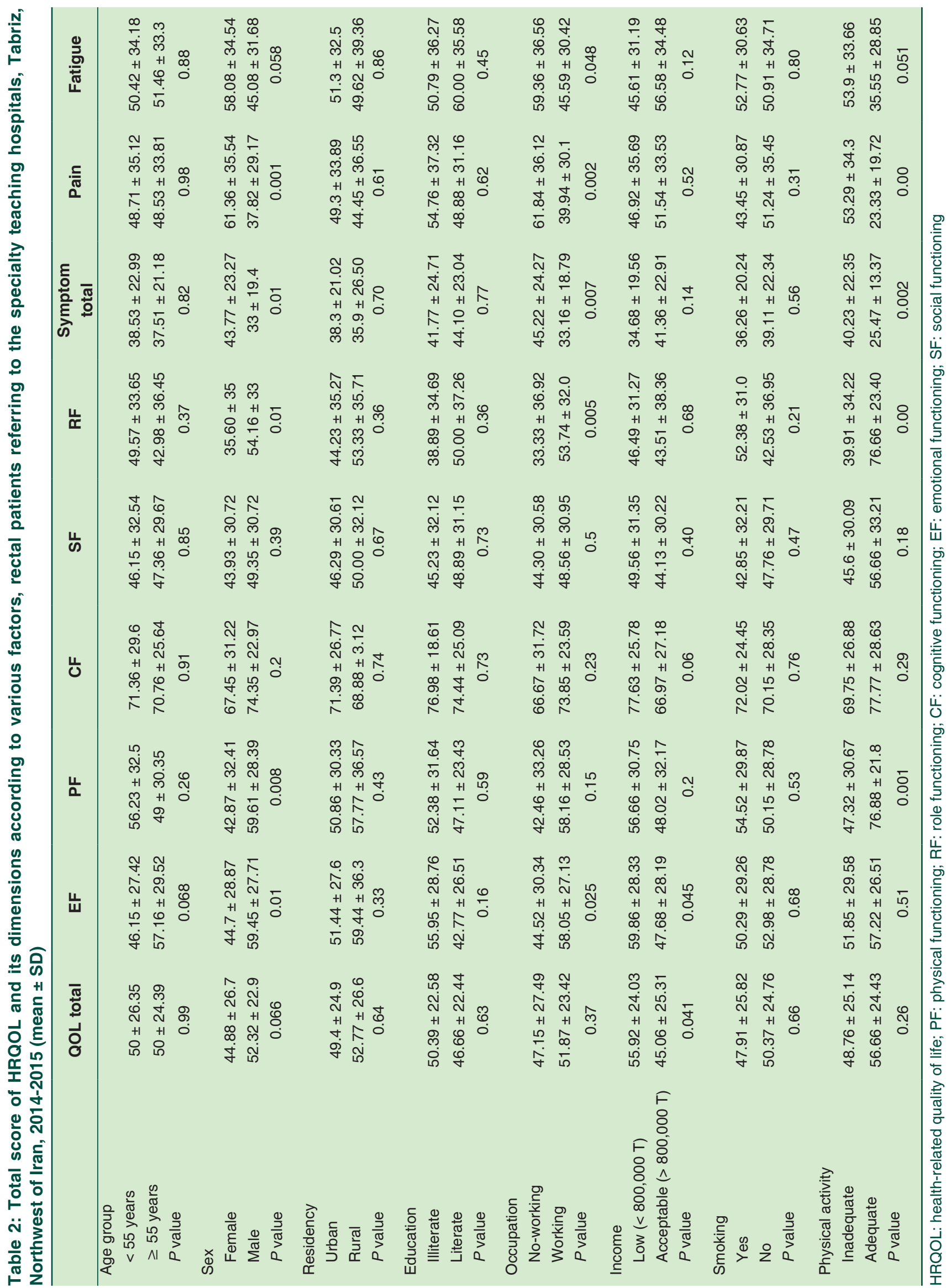




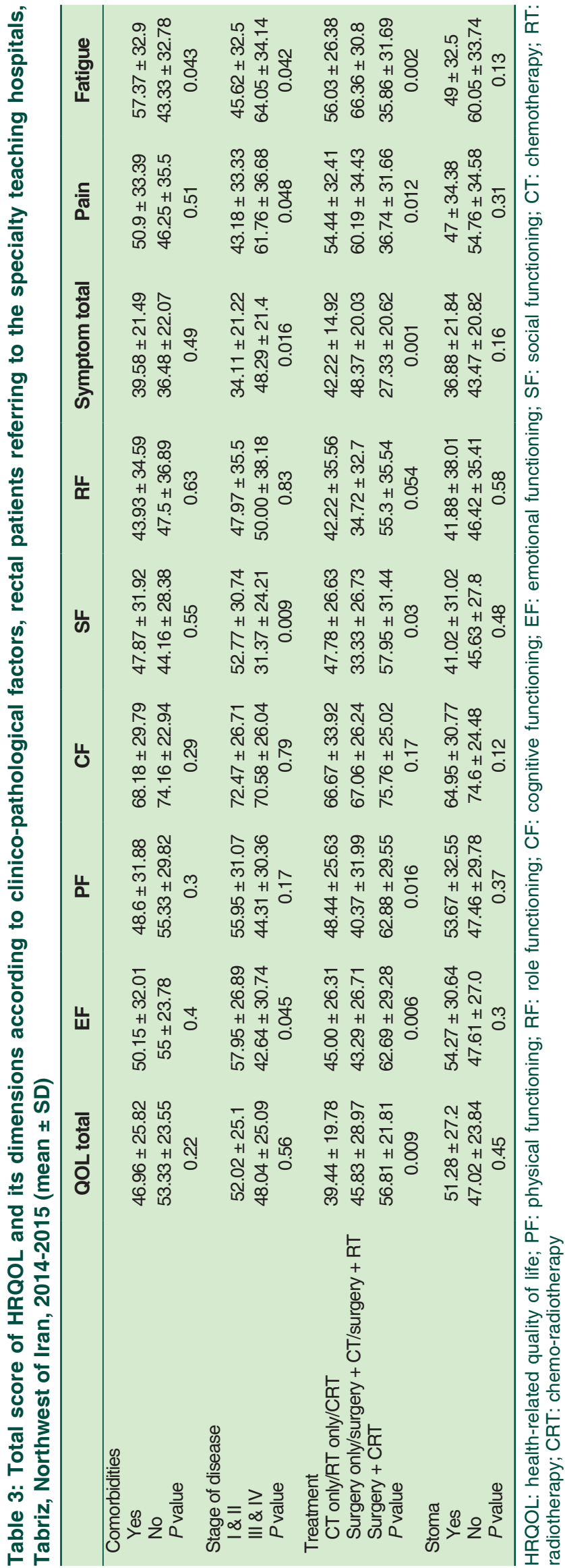

fatigue. Those with stage III and IV had significantly lower scores in EF and SF dimensions and had significantly higher scores of symptoms total, pain and fatigue compared to patients with lower scores. Patients with stoma had better scores of QOL and reported less pain, and fatigue and had a lower score of symptom total.

Table 4 shows the results of a multivariate linear regression model that was performed to identify predictors of HRQOL. As it can be seen in this table income and treatment option were predictors of $\mathrm{QOL}$ $\left(R^{2}=9 \%\right)$. Income was negatively predictive of $\mathrm{QOL}$ score. Stage of disease and treatment option were associated with EF scores $\left(R^{2}=18 \%\right)$. Stage of disease was negatively predictive of poorer EF score, however surgery plus CRT was a predictor of better EF functioning. Gender, treatment option and physical activity remained significant predictors of better $\mathrm{PF}$ functioning $\left(R^{2}=23 \%\right)$. Stage of disease and treatment option were predictors of SF dimension score $\left(R^{2}=\right.$ $11 \%)$. Physical activity was the only predictors of RF functioning score $\left(R^{2}=17 \%\right)$. Treatment option and physical activity were negatively predictive of total symptom score $\left(R^{2}=22 \%\right)$.

Predictors of pain were a treatment option, physical activity and stage of disease $\left(R^{2}=25 \%\right)$. Treatment other than surgery + CRT, insufficient physical activity and higher stage of disease were associated with higher scores of pain. Treatment option, comorbidities, disease stage, and physical activity were predictors of fatigue score $\left(R^{2}=27 \%\right)$.

\section{DISCUSSION}

The aim of the current study was to assess the predictors of HRQOL among patients with rectal cancer. To our knowledge, limited studies examined the HRQOL among CRC patients including a range of different clinico-epidemiological factors, and especially among patients with rectal cancer separately.

We found that the overall score of $\mathrm{QOL}$ was low in our patients (48.2). Which was lower the total score reported from studies regarding CRC patients in other countries $^{[14,15]}$ and in Iran which reported the total scores of higher than $70^{[16,17]}$. The global QOL in a study by Engel et al. ${ }^{[10]}$ among rectal cancer patients was reported 65.3 in the first year of diagnosis. It was reported 54.5 in a study by Zając et al. ${ }^{[18]}$ among patients with stoma due to rectal cancer. Studies showed that the score of QOL is getting better over time ${ }^{[19]}$. It has been shown that the QOL among disease-free survivors of rectal cancer after two years 
Table 4: Association between HRQOL and its dimensions and sociodemographic and clinical factors

\begin{tabular}{|c|c|c|c|c|c|c|}
\hline \multirow{2}{*}{ Dependent variable } & \multirow{2}{*}{ Covariates } & \multicolumn{3}{|c|}{ Regression coefficient, $R$} & \multicolumn{2}{|c|}{$95 \% \mathrm{Cl}$} \\
\hline & & B (SE) & Beta & $P$ & Lower bound & Upper bound \\
\hline QOL total & Income & $-11.44(5.14)$ & -0.22 & 0.029 & -21.66 & -1.23 \\
\hline$R^{2}=9 \%$ & Treatment & $8.73(3.47)$ & 0.25 & 0.014 & 1.83 & 15.63 \\
\hline EF & Stage of disease & $-14.99(7.1)$ & -0.21 & 0.03 & -29.14 & -0.83 \\
\hline$R^{2}=18 \%$ & Treatment & $8-81(4.09)$ & 0.23 & 0.035 & 0.65 & 16.96 \\
\hline PF & Sex (malelfemale) & $14.55(5.84)$ & 0.23 & 0.015 & 2.94 & 26.16 \\
\hline \multirow[t]{2}{*}{$R^{2}=23 \%$} & Treatment & $9.07(3.91)$ & 0.21 & 0.023 & 1.29 & 16.85 \\
\hline & Physicalactivity & $26.07(7.67)$ & 0.31 & 0.001 & 10.82 & 41.32 \\
\hline SF & Stage of disease & $-22.42(7.90)$ & -0.29 & 0.006 & -38.15 & -6.68 \\
\hline$R^{2}=11 \%$ & Treatment & $9.42(4.32)$ & 0.22 & 0.032 & 0.80 & 18.03 \\
\hline \multicolumn{7}{|l|}{$R^{2}=17 \%$} \\
\hline \multirow{2}{*}{$\begin{array}{l}\text { Symptom total } \\
R^{2}=22 \%\end{array}$} & Treatment & $-9.14(2.94)$ & -0.32 & 0.003 & -15.00 & -3.27 \\
\hline & Physicalactivity & $-15.51(5.98)$ & -0.26 & 0.011 & -27.44 & -3.59 \\
\hline \multirow{3}{*}{$\begin{array}{l}\text { Pain } \\
R^{2}=25 \%\end{array}$} & Treatment & $-8.83(4.63)$ & -0.18 & 0.06 & -18.05 & 0.39 \\
\hline & Physicalactivity & $-31.18(9.41)$ & -0.31 & 0.001 & -49.93 & -12.43 \\
\hline & Stage of disease & $21.146(8.33)$ & 0.24 & 0.013 & 4.55 & 37.74 \\
\hline Fatigue & Treatment & $-14.94(4.56)$ & -0.33 & 0.002 & -24.03 & -5.85 \\
\hline \multirow[t]{3}{*}{$R^{2}=27 \%$} & Physicalactivity & $-22.68(9.29)$ & -0.25 & 0.017 & -41.19 & -4.17 \\
\hline & Stage of disease & 23.66 (8.23) & 0.29 & 0.005 & 7.26 & 40.06 \\
\hline & Comorbidities & $-14.49(6.73)$ & -0.21 & 0.035 & -27.90 & -1.07 \\
\hline
\end{tabular}

HRQOL: health-related quality of life; Cl: confidence interval; PF: physical functioning; RF: role functioning; EF: emotional functioning; SF: social functioning

was higher than that in the general population ${ }^{[20]}$. The difference between our results and other studies might be explained by the time of recruitment of the study population. In our study, all patients were diagnosed less than one year and some were receiving active treatment, and some patients with advanced stages were also included. Our results showed that younger and older patients had almost the same score of the overall QOL and its dimensions except emotional dimension which was lower in younger patients. It in line with the results of other studies which showed the poorer emotional performance of younger patients ${ }^{[9,21]}$. We found that females generally had poorer QOL than men, the same reported by Li et al. ${ }^{[0]}$ but some studies reported the lower social wellbeing score among men, that might be because they used different instrument for assessment of the $\mathrm{QOL}^{[21]}$.

In the current study income and treatment options were predictors of the total score of QOL. Income was negatively predictive of QOL score, surgery plus CRT was positively related to the higher score of the $\mathrm{QOL}$ total score. The QOL of the long-term survival group was associated with lifestyle factors, symptoms and usual activity, and the presence of a stoma was not the matter. However, QOL one year after surgery was associated with adjuvant therapy ${ }^{[22]}$.

In this study, stage of disease was negatively predictive of EF and SF, but positively predictive of pain and fatigue. Treatment option was predictive of all QOL dimensions (except CF) and pain and fatigue. Those who received surgery plus CRT had better performance and lower pain and fatigue. There is evidence that type of surgery affects the QOL after surgery among patients with cancer of the rectum. Evidence showed that cancer-free patients with rectal cancer who had no terminal abdominal stoma showed a better score in all categories of the QOL 30 after five years $^{[23]}$. In addition, it has been shown that sphincter sparing operations are higher among patients who undergone neoadjuvant chemo-radiotherapy and they show better scores in $\mathrm{QOL}^{[24]}$. However, in this study we combined neoadjuvant and adjuvant therapies, therefore the reason for such results cannot be clearly concluded. In this study, patients with comorbidities had poorer scores on total QOL and its dimensions and showed higher pain and fatigue, however, in the final model it was predictive of only fatigue. Studies also showed a poorer performance of QOL among those with comorbidities ${ }^{[25]}$.

Another finding of this study was the association between physical activity and the score of PF and RF dimensions, those with sufficient physical activity had better scores in these dimensions, and it was also negatively predictive of symptom total, pain and fatigue. Those with sufficient physical activity had lower scores in symptom total, had lower pain and fatigue. Studies demonstrated the positive effect of physical activity on quality of life among patients with $\mathrm{CRC}^{[26]}$.

This study has some limitations, we included patients from teaching hospitals, those who were admitted to private hospitals might be from higher socioeconomic 
status, therefore association between income and score of QOL might be affected. At the time of this study we could not access to surgery profile of the patients, then the information about preserving sphincter was not available, however evidence showed that sphincter-ablating procedures do not necessarily reduce $\mathrm{QOL}$ in patients with rectal cancer ${ }^{[21]}$.

This study reported a relatively low score of $\mathrm{QOL}$ among patients with rectal cancer compared to studies from other countries. In general treatment option and stage of disease, and physical activity were important predictive factors of QOL. The presence of a modifiable factor is an opportunity for interventional strategies to improve the QOL via physical activity modification. Organised screening is recommended to improve the stage at presentation and concordance with treatment guidelines is also recommended.

\section{DECLARATIONS}

\section{Authors' contributions}

Involved in design of the protocol of the study and all drafts of the manuscript, and reviewed and agreed the final draft of the manuscript: N. Aminisani, M. Fatemi, P. Sarbakhsh, A. Nikanfar, A. Eftekharsadat, E. Jafari Did data collection and analysis: M. Fatemi, E. Jafari Supervised and supported data collection: N. Aminisani, A. Nikanfar, A. Eftekharsadat

Supervised the data analysis: N. Aminisani, P. Sarbakhsh

\section{Financial support and sponsorship}

This study was funded by the Haematology and Oncology Research Centre and Centre for Training and Research on Health Management of Tabriz University of Medical Sciences.

\section{Conflicts of interest}

There are no conflicts of interest.

\section{Patient consent}

At the beginning of the study, informed consent was obtained in written from all of the participants.

\section{Ethics approval}

The study was conducted in accordance with the declaration of Helsinki and had ethics approval from the Tabriz University of Medical Science Ethical Review Committee (Ethical ID numbers: TBZMED. REC.5/4/11460).

\section{REFERENCES}

1. Torre LA, Bray F, Siegel RL, Ferlay J, Lortet-Tieulent J, Jemal A. Global cancer statistics, 2012. CA Cancer J Clin 2015;65:87-108.
2. Jemal A, Bray F, Center MM, Ferlay J, Ward E, Forman D. Global cancer statistics. CA Cancer J Clin 2011;61:69-90.

3. Ozols RF, Herbst RS, Colson YL, Gralow J, Bonner J, Curran WJ Jr, Eisenberg BL, Ganz PA, Kramer BS, Kris MG, Markman M, Mayer RJ, Raghavan D, Reaman GH, Sawaya R, Schilsky RL, Schuchter LM, Sweetenham JW, Vahdat LT, Winn RJ; American Society of Clinical Oncology. Clinical cancer advances 2006: major research advances in cancer treatment, prevention, and screening -- a report from the American Society of Clinical Oncology. J Clin Oncol 2007;25:146-62

4. Obias VJ, Reynolds HL Jr. Multidisciplinary teams in the management of rectal cancer. Clin Colon Rectal Surg 2007;20:143-7.

5. Vignali A, De Nardi P. Multidisciplinary treatment of rectal cancer in 2014: where are we going? World J Gastroenterol 2014;20:11249-61.

6. Bowling A. Measuring disease: a review of disease-specific quality of life measurement scales. England: Open University Press; 2001.

7. Marventano S, Forjaz M, Grosso G, Mistretta A, Giorgianni G, Platania A, Gangi S, Basile F, Biondi A. Health related quality of life in colorectal cancer patients: state of the art. BMC Surg 2013;13 Suppl 2:S15.

8. Grumann MM, Noack EM, Hoffmann IA, Schlag PM. Comparison of quality of life in patients undergoing abdominoperineal extirpation or anterior resection for rectal cancer. Ann Surg 2001;233:149-56.

9. Li X, Song X, Chen Z, Li M, Lu L, Xu Y, Zhan W, He Y, Xu K Quality of life in rectal cancer patients after radical surgery: a survey of Chinese patients. World J Surg Oncol 2014;12:161.

10. Engel J, Kerr J, Schlesinger-Raab A, Eckel R, Sauer H, Hölzel D Quality of life in rectal cancer patients: a four-year prospective study. Ann Surg 2003;238:203-13.

11. Ministry of Health and Medical Education. Cancer office. Cancer registration country reports 2009. Iran, 2012. Available in Persian from: crc.tums.ac.ir. [Last accessed on 26 September 2017]

12. Nikbakht HA, Aminisani N, Asghari-Jafarabadi M, Hosseini SR Trends in the incidence of colorectal cancer and epidemiologic and clinical characteristics of survivors in babol city in 2007-2012. $J$ Babol Univ Med Sci 2015;17:7-14.

13. Ali Nikbakht H, Aminisani N, Asghari Jafarabadi M, Hosseini SR Quality of life and its determinants among colorectal cancer survivors. J Kermanshah Univ Med Sci 2015;19:84-92.

14. Tsunoda A, Nakao K, Watanabe M, Matsui N, Tsunoda Y. Healthrelated quality of life in patients with colorectal cancer who receive oral uracil and tegafur plus leucovorin. Jpn J Clin Oncol 2010;40:412-9.

15. Nicolussi AC, Sawada NO. Quality of life of patients with colorectal cancer who were receiving complementary therapy. Acta Paulista de Enfermagem 2009;22:155-61.

16. Akhondi-Meybodi M, Akhondi-Meybodi S, Vakili M, Javaheri Z. Quality of life in patients with colorectal cancer in Iran. Arab J Gastroenterol 2016;17:127-30.

17. Momeni M, Ghanbari A, Jokar F, Rahimi A, Leyli EK. Predictors of quality of life in patients with colorectal cancer in Iran. Indian $J$ Cancer 2014;51:550-6.

18. Zając O, Spychała A, Murawa D, Wasiewicz J, Foltyn P, Połom K. Quality of life assessment in patients with a stoma due to rectal cancer. Rep Pract Oncol Radiother 2008;13:130-4.

19. Schmidt CE, Bestmann B, Küchler T, Longo WE, Kremer B. Ten-year historic cohort of quality of life and sexuality in patients with rectal cancer. Dis Colon Rectum 2005;48:483-92.

20. Rauch P, Miny J, Conroy T, Neyton L, Guillemin F. Quality of life among disease-free survivors of rectal cancer. $J$ Clin Oncol 2004:22:354-60

21. Smith-Gagen J, Cress RD, Drake CM, Romano PS, Yost KJ, Ayanian JZ. Quality-of-life and surgical treatments for rectal cancer -- a longitudinal analysis using the California Cancer Registry. 
Psychooncology 2010;19:870-8.

22. Hamashima C. Long-term quality of life of postoperative rectal cancer patients. J Gastroenterol Hepatol 2002;17:571-6.

23. Allal AS, Gervaz P, Gertsch P, Bernier J, Roth AD, Morel P, Bieri $\mathrm{S}$. Assessment of quality of life in patients with rectal cancer treated by preoperative radiotherapy: a longitudinal prospective study. Int $J$ Radiat Oncol Biol Phys 2005;61:1129-35.

24. Boland PM, Fakih M. The emerging role of neoadjuvant chemotherapy for rectal cancer. $J$ Gastrointest Oncol 2014;5:362-73.

25. Wang JW, Sun L, Ding N, Li J, Gong XH, Chen XF, Yu DH, Luo $\mathrm{ZN}$, Yuan ZP, Yu JM. The association between comorbidities and the quality of life among colorectal cancer survivors in the People's Republic of China. Patient Prefer Adherence 2016;10:1071-7.

26. Lynch BM, van Roekel E, Vallance JK. Physical activity and quality of life after colorectal cancer: overview of evidence and future directions. Expert Rev Qual Life Cancer Care 2016;1:9-23. 